Artikel Konseptual

\title{
PEMANFAATAN CAGAR BUDAYA DI KABUPATEN PACITAN SEBAGAI MEDIA PENUNJANG PENDIDIKAN SEJARAH
}

\section{Blasius Suprapta}

blasius.suprapta.fis.um@g.mail.com atau blasius.suprapta.fis.@um.ac.id

Jurusan Sejarah, Fakultas Ilmu Sosial, Universitas Negeri Malang

\begin{abstract}
The cultural heritage of Pacitan Regency is concentrated in Punung area. Most of the cultural heritage Punung is a prehistoric cultural heritage, consisting of paleolitik sites, mesolitik and neolitik sites. Paleolithic sites are widespread throughout Kali Baksoka, while the mesolithic sites include the residential cave sites Song Terus, Song Keplek and Song Gupuh. The neolithic sites include among others Ngrijangan neolithic workshop and Ngrijangan Sengon. Some of these sites have been designated as a cultural heritage and can be used as a medium for educational support. Paleolitik Kali Baksoka cultural heritage sites can be used as supporting media of paleolithic cultural level, cultural site of Song Terus and Song Keplek as a medium of life support of mesolitic cultural level and cultural heritage of Ngrijangan site as supporting life of neolithic culture level.
\end{abstract}

Key words: Cultural heritage, Kali Baksoka, Song Terus, Song Keplek, supporting educational media

\section{PENDAHULUAN}

Pemanfaatan Cagar Budaya sebagai media penunjang pendidikan sejarah sejalan dengan Undang Undang Republik Indonesia Nomor 11 Tahun 2010 Tentang Cagar Budaya telah diatur dalam Pasal 85, ayat (1) bahwa : Pemerintah, Pemerintah Daerah dan setiap orang dapat memanfaatakan Cagar Budaya untuk kepentingan agama, sosial, pendidikan, ilmu pengetahuan, teknologi, kebudayaan dan pariwisata. Selanjutnya dalam Pasal 85 , ayat (2) dikemukakan bahwa: Pemerintah dan Pemerintah Daerah memfasilitasi pemanfaatan dan promosi Cagar Budaya yang dilakukan oleh setiap orang (UU RI Nomor 11 Th.2010 Tentang Cagar Budaya). Sejalan dengan Undang- Undang Republik Indonesia Nomor 11 Th. 2010 Pasal 85. ayat (1) dan (2) tersebut, maka Dinas Kebudayaan dan Pariwisata, Propinsi Jawa Timur melakukan Kegiatan Peningkatan Partisipasi Masyarakat di Sekitar Cagar Budaya dan salah satu tema yang diusung yaitu Pemanfaatan Cagar Budaya di Kabupaten Pacitan Sebagai Media Penunjang Pendidikan. Fokus kegiatan ini akan dikonsentrasikan di lingkungan Cagar Budaya Situs Paleolitik Sungai Baksoka, Situs Gua Hunian Mesolitik Song Terus dan Situs Perbengkelan Neolitik Ngijangan, Punung, Kabupaten Pacitan. Titik penting kegiatan yaitu menyosialisasikan bahwa situs-situs tersebut mempunyai arti penting akademik sebagai penunjang media pendidikan utama yang berkaitan dengan Kompetensi Dasar (KD) 3.1 dan 3.2 matapelajaran Sejarah Indonesia yang berhubungan 
dengan kehidupan manusia Indonesia pada Masa Praaksara atau Masa Prasejarah sekitar 1,6 juta tahun yang lalu hingga \pm 120 tahun sebelum sekarang (Simanjuntak 2002:201).

Untuk mensosialisakan bahwa Cagar Budaya Situs Paleolitik Sungai Baksoka, Situs Gua Hunian Mesolitik Song Terus dan Situs Perbengkelan Neolitik Ngijangan, yang tersebar di daerah Punung, tersebut dapat dipakai sebagai sarana media penunjang untuk menjelaskan salah satu aspek kehidupan manusia Indonesia pada Masa Praaksara atau Masa Prasejarah, maka akan diuraikan dulu tentang penjelasan akademik deskripsi situssitus tersebut. Selanjutnya dilakukan kegiatan kunjungan situs sebagai bagian pembelajaran outdoor learning untuk bersama-sama mengenali jejak-jejak aktifitas sosialekonomi manusia pada Masa Praaksara melalui jejak-jejak lingkungan alam situs Kala Plestosen, jejak-jejak kebudayaan material yang ditinggalkan serta jejak-jejak awal kehidupan religi pada Masa Praaksara pada lingkungan gua karst. Dengan demikian akan tergambar secara jelas proses pembelajaran outdoor learning bahwa Situs Paleolitik Sungai Baksoka, Situs Hunian Mesolitik Gua Song Terus dan Situs Perbengkelan Neolitik Ngrijangan sebagai media penunjang pendidikan dianggap sangat penting khususnya penunjang media Pembelajaran Sejarah yaitu kehidupan sosial-ekonomi manusia Masa Praaksara atau Masa Prasejarah Indonesia. Dengan demikian kita dapat mengonstruksi secara nyata lingkungan alam dimana manusia Masa Praaksara bertempat tinggal serta beraktifitas dan hal ini salah satunya dapat menimbulkan motivasi serta keefektivan pembelajaran berbasis pada model pembelajaran outdoor learning. Sebagai langkah pertama akan kami paparkan secara akademik tentang hasil penelitian deskripsi masing-masing situs, disertai rekonstruksi tentang kehidupan sosial-ekonomi manusia pada Masa Praaksara yaitu Paleolitik, Mesolitik dan Neolitik (Soejono, 1984).

\section{BENTANGAN CAGAR BUDAYA MASA PRAAKSARA PACITAN}

\section{Situs Paleolitik Sungai Baksoka}

Kawasan Cagar Budaya Situs Paleolitik Kali Baksoka, terletak di daerah Punung, kurang lebih $30 \mathrm{~km}$ di barat laut Kota Pacitan. Secara administratif kawasan Cagar Budaya tersebut merupakan bagian wilayah Kecamatan Punung, Kabupaten Pacitan, Propinsi Jawa Timur. Secara geografis, kawasan Cagar Budaya tersebut merupakan bagian kawasan Pegunungan Kapur Selatan yakni Pegunungan Gunung Sewu yang dikelilingi oleh jaringan hidrografis besar dan membentang berbentuk jalur sempit pada arah barat-timur, berbatasan dengan Samudra Hindia. Pegunungan Seribu (Gunung Sewu) tersebut dikelilingi dataran alluvial dan barisan pegunungan yang ketinggiannya tidak melebihi 800 
m di atas permuakaan laut (Barstra, 1976) yaitu sebelah timur dekat Sungai Opak, dataran aluvial Yogyakarta, sebelah utara, dataran rendah Wonosari serta Baturetno, dan sebelah barat dataran Wonosari yang membentuk suatu kesatuan dinamakan Gunung Kidul.

Pegunungan Gunung Sewu terbentuk oleh batu gampingan koral yang telah mengalami pengangkatan secara berturut-turut sejak Kala Miosen dari Wonosari di barat hingga Pacitan termasuk Punung di timur. Pengangkatan terakhir berlangsung pada Kala Plestosen Tengah. Bedasarkan penelitian Lehmamn (1936) serta van Bemmelen (1949) menunjukkan bahwa morfogenesis barisan Pegunungan Sewu bermula dari Kala Miosen di atas struktur yang lebih tua yang terdiri atas unsur-unsur vulkanis. Sehubungan dengan itu pembentukan Pegunungan Sewu disebabkan oleh proses mekanis yang bersifat epirogenis dan fisika-kimia yang berkaitan dengan erosi. dan proses pengikisan serta erosi telah berlangsung sejal awal Kala Kuarter (Lehmann 1936).

Proses erosi dan cekungan lembah-lembah kecil, serta doline (lubang yang berbentuk corong), tampaknya dimulai dengan pembentukan sungai-sungai yang sangat tua seperti Kali Opak-Oya di barat dan Kali Baksoka, Punung, Pacitan di timur (Bartstra, 1976). Proses kartifikasi mungkin berlangsung cukup dini dan mencapai aspeknya yang sekarang pada Kala Plestosen Tengah. Hipotesis ini dikemukakan setelah penemuan sisa-sisa fosil vertebrata dalam kategori Fauna Trinil yang berhasil ditemukan olek von Koenigswald (1936). Pada lapisan kala Plestosen Tengah di Kali Baksoka, fosil binatang kategori Fauna Trinil ini ditemukan satu konteks dengan alat-alat paleolitik dalam jumlah yang sangat melimpah. Alat-alat paleolitik dalam jumlah yang melimpah tersebut berkaitan dengan hasil budaya manusia purba Pithecanthropus erectus.

Kawasan Cagar Budaya Paleolitik Kali Baksoka telah mendapat perhatian besar oleh para prehistoris tingkat dunia, antara lain von Koenigswald (1936), H.L.Movius (1948), H.R.van Heekeren (1954) dan G.J.Barstra (1976). Dalam konteks budaya paleolithik Asia Timur, alat-alat paleolithik Kali Baksoka oleh L.Movius, dimasukkan sebagai budaya chopper -chopping-tools compleks dan kemudian di dunia prasejarah dikenal dengan "Kebudayaan Pacitan" atau Pacitanian. Sejak saat itulah Kebudayaan Pacitan yakni kawasan Cagar Budaya Paleolitik Kali Baksoka menjadi terkenal serta menjadi ajang kegiatan penelitian ahli-alhi paleolitik, paleontologi dan geologi.

Penelitian tentang alat-alat lithik di Kali Baksoka, Punung, Pacitan, Jawa Timur diawalaoleh von Konigswald (1936, 52-60) pada th. 1935 bersama M.W.F.Tweede dan beliau berhasil mengumpulkan alat-alat paleolithik sebanyak 2.000 buah di dasar Kali Baksoka. Oleh von Konigswald alat-alat lithik tersebut digolongkan sebagai alat paleolithik yang bercorak Chellean, yakni suatu tradisi yang berkembang pada tingkat awal paleolithik di Eropa. Pendapat ini kemudian disanggah oleh Hallam L.Movius, Jr, setelah pada 
th.1948, Movius berhasil menyatakan bahwa temuan alat-alat pelolitik Punung tersebut sebagai salah satu corak perkembangan kapak perimbas (chopper-chopping tools compleks) di Asia Timur dan kemudian alat-alat paleolithik di Punung tersebut dikenal sebagai Kebudayaan Pacitan atau Pacitanian yang dikategorikan sebagai budaya batu paling awal di Indonesia (Soejono, 1984: 88-89).

Dalam kaitannya dengan penelitian alat-alat paleolitik di dasar Kali Baksoka, von Koenigswald juga melakukan penelitian sebaran fosil-fosil binatang vertebrata. Sebaran fosil-fosil yang dimaksud, ditemukan von Koenigswald di Desa Tabukan (masih satu konteks dengan Kali Baksoka) terdiri atas fosil-fosil gajah (Stegodon sp, Elephas namadicus), babi rusa, tapir, beruang, kijang (Echinosorex) serta gigi-gigi dari berbagai jenis kera (Simia), Syphalangus dan Hylobates. Menurut Koenigswald (1937:32) fosil-fosil yang ditemukan dalam konteks Kali Baksoka tersebut tergolong Fauna Trinil, sehingga diperkirakan binatang vertebrata tersebut hidup pada Kala Plestosen Tengah. Atas dasar temuan tersebut, maka alat-alat paleolitik yang ditemukan di dasar Kali Baksoka tersebut digolongkan alat batu yang berkembang pada Kala Plestosen Tengah, sehingga keberadaannya dapat dihubungkan dengan kehidupan manusia purba praakasara Pithecanthropus erectus, dalam fase perkembangan sosial-ekonomis Masa Berburu dan Mengumpul Makanan Tingkat Sederhana, walaupun fosil manusia purba tersebut di kawasan Kali Baksoka hingga saat ini belum ditemukan.

Alat-alat batu paleolitik yang telah dikumpulkan oleh Koenigswald, kemudian telah diklasifikasikn oleh Movius menjadi alat-alat paleolitik kapak perimbas, kapak penetak, pahat genggam, kapak genggam awal, kapak genggam, alat serpih yang belum terpakai, alat serpih yang telah terpakai, batu inti dan aneka ragam alat - alat lain (Soejono 1984:92). Penelitian lanjutan Budaya Pacitan, di dasar Kali Baksoka dilanjutnya oleh van Heekeren (1954), Soejono dan Basoeki pada th.1953 dan 1954. Daerah lembah Kali Baksoka diteliti kembali dan ditambah tempat-tempat baru yang mengandung alat-alat Budaya Pacitan, dan tempat-tempat baru yang mengandung temuan alat-alat Budaya Pacitan telah ditemukan kembali di sekitar Desa Tabuhan yang terletak kurang lebih $6 \mathrm{~km}$ barat laut Punung. Kegiatan ekskavasi juga telah dilakukan di Gua Song Terus (Tabuhan) dalam kaitannya mencari persebaran alat- alat paleolitik Pacitanian pada th.1953, antara lain berhasil dihimpun sejumlah temuan berupa sisa-sisa tulang binatang seperti tengkorak monyet serta geligi gajah: Elephas maximus, dengan demikian tidak ditemukan alat-alat Budaya Pacitanian (Soejono, 1984: 93).

Penelitian sebaran alat-alat paleolitik Pacitanian dilanjutkan di sekitaran lembah Kali Baksoka dan di dasar sungai dekat Janglot telah ditemukan alat-alat batu di undakundak sungai, pada ketinggian $4 \mathrm{~m}$ dan $15-20 \mathrm{~m}$ di atas dasar sungai. Alat-alat paleolitik Pacitanian juga dikumpul dari dasar Kali Ngambar - anak sungai Kali Baksoka dan dari 
lapisan kerakal yang berada di tepian sungai, kira-kira berada pada ketinggian 1,5 m. Pada th.1953 di celah sebuah reruntuhan karang gamping tepi Kali Gede pertama kali ditemukan jenis kapak perimbas dan penelitian th.1953 hingga th.1954 menghasilkan sejumlah alat-alat batu dari dasar sungai serta lapisan-lapisan kerakal tepi sungai pada ketinggian antara 1,5 m-2 m. Adapun tempat-tempat tinggi yang mengandung alat-alat batu Pacitanian adalah Kali Sirikan, Kali Sunglon di Desa Kiut dan tepian Kali Sunglon dekat Desa Klepu.

Penelitian intensifdilakukan pada th. 1972 dan th.1973 untuk memecahkan masalah-masalah mengenai undak-undak sungai, terutama mengenai usia dan masa perkembangan alat-alat paleolitik Pacitanian. Penelitian lanjutan dilaksanakan bertahap-tahap oleh Barstra serta Basoeki di lembah Kali Baksoka, di daerah Tabuhan dan lembah-lembah Kali Wuni serta Kali Pasang (Soejono, 1984:96).

Penelitian lanjutan dilakukan oleh Samudra (1983) serta Surono et.al (1992) untuk mendeskripsikan undak-undak kali Baksoka. Tahun 1983 dilanjutkan oleh Widianto et.al. dan tahun 1995 oleh Simanjuntak untuk menentukan luasan sebaran alat-alat paleolitik Pacitanian di Kali Baksoka. Dari Sejarah penelitian tersebut, diketahui bahwa Kawasan Cagar Budaya Paleolitik Kali Baksoka, Punung, Pacitan dipandang penting dari sisi pengenbangan ilmu pengetahuan utamanya ilmu palenotologi, geologi, prasejarah serta evolusi budaya pada tingkat awal pada kurum waktu yang oleh Soejono disebut tahapan kehidupan manusia purba Masa Berburu dan Mengumpul Makanan Tingkat Sederhana dengan budaya tradisi paleolitik. Soekmono maupun Heekeren menempatkan budaya tradisi megalitik Sungai Baksoka sebagai salah satu aspek kehidupan manusia pada Zaman Paleolithik dan menamakannya sebagai Budaya Pacitan (Pacitanian) dalam konteks budaya paleolithik Asia Tenggara (Heekeren 1957:27-34).

Penelitian lanjutan dilakukan oleh Team Pusat Penelitian Arkeologi Nasional pada th 1996 hingga 1999 antara lain telah berhasil memperkirakan pertanggalan relatis situs paleolithik Kali Baksoka. Berdasarkan kajian team PUSLIT ARKENAS diketahui pertanggalan relatif lapisan Kali Basoka diperkirakan minimal 11.000 tahun yang lalu. Kemudian berdasarkan temuan lapisan paling bawah Gua Song Terus diperkirakan minimal berusia 180.000 tahun yang lalu dan diperkirakan masuk lapisan Akhir Kala Plestosen Tengah. Dengan demikian alat-alat paleolitik Pacitanian dapat dikaitkan dengan kehidupan manusia purba Pithecanthropus erectus hingga jenis manusia purba Pithecantrophus soloensis (Simanjuntak 2002:84-85).

Selain itu, mengingat persebaran alat-alat paleolitik Kali Baksoka bergitu padat dan dalam kondisi refrest diperkirakan di sepanjang Kali Baksoka pada Kala Plestosen Tengah difungsikan sebagai tempat perbengkelan terbuka sekaligus sebagai hunian manusia purba jenis Pitehcenhtrophus erectus - Pitehcanthrophus soloensis. Dengan demikian 
Cagar Budaya Situs Paleolitik Kali Baksoka mencerminkan salah satu model lingkungan yang berkaitan dengan perihal kehidupan sosial-ekonomis manusia Praaksara Indonesia pada tahapan kehidupan sosial-ekonomis Masa Berburu dan Mengumpul Makan Tingkat Lanjut yang dikenal dengan budaya tradisi paleolitik dan di Pacitan dikenal dengan Kebudayaan Pacitan atau Pacitanian (Simanjuntak 2002:85).

Dalam konteks Kompetensi Dasar (KD) 3.1 dan 3.2 matapelajaran Sejarah Indonesia Kurikulum 2013, Cagar Budaya Situs Paleolitik Sungai Baksoka merupakan penunjang media pembelajaran sejarah yang terkait dengan penjelasan kehidupan sosial-ekonomi manusia purba pada Masa Berburu dan Mengumpul Makanan Tingkat Sederhana. Situs tersebut merupakan sumber belajar outdoor learning yang mempresentasikan kondisi lingkungan alam Kala Plestosen Tengah di saat manusia purba beraktivitas. Juga merupakan sumber belajar outdoor learning tentang kearifan lokal yakni pengetahuan pembuatan alat-alat dan macam-macam alat-alat yang diproduksi manusia purba yakni Pithecanthrophus erectus, untuk mempertahankan hidupnya pada Masa Berburu dan Mengumpul Makanan Tingkat Sederhana atau Zaman Paleolitik.

\section{Situs Hunian Mesoltik Gua Song Terus}

Cagar Budaya Situs Hunian Mesolitik Gua Song Terus merupakan salah satu jenis situs hunian mesolitik dan gua ini pertama kali telah diteliti oleh R.P Soejono dan H.R.van Heekeren pada th.1954 (Heekeren 1992:8). Penelitian kemudian dilanjutkan oleh Pusat Penelitian dan Pengembangan Arkeologi Nasional pada th.1994 bekerja sama dengan Muséum National D'histoire Naturelle, Perancis. Hasil penelitian antara lain dapat menjelaskan proses terbentuknya Gua Song Terus hingga menjadi tempat hunian tertua di kawasan Asia Tenggara bagi jenis manusia Homo sapiens awal setelah fase kehidupan manusia purba Pithecanthrophus erectus.

Hasil penelitian th.1994 tersebut antara lain dapat menjelaskan tentang proses pembentukan gua hingga menjadi hunian awal manusia pada pase sosial-ekonomi Masa Berburu dan Mengumpul Makanan Tingkat Lanjut. Secara umum proses pembentukan gua-gua hunian mesolitik di Gunung Sewu termasuk juga Gua Hunian Mesolitik Song Terus yaitu pertama diawali dengan proses pengangkatan gugusan gamping Gunung Sewu ke atas permukaan air laut dan hal ini antara lain mengakibatkan lapisan-lapisan sedimen yang belum tersementasi sempurna mengalami perekahan zona lemah batuan. Proses kimiawi mengakibatkan perekahan bertambah lebar dan dalam serta bebentuk tidak beraturan. Pengaruh perubahan lingkungan, baik yang disebabkan oleh gerakan pengangkatan maupun oleh iklim, menyebabkan pelarutan berjalan intensip sampai jauh ke dalam tanah. Kejadian ini berlangsung terus menerus, sehingga mengakibatkan terjadinya pergantian bentuk lorong antara bidang tegak dengan bidang datar zona lemah 
batuan. Dalam pengangkatan daratan, gua ikut terangkat hingga di atas permukaan air tanah atau di atas muka dasar erosi. Dengan demikian dapat dikatakan bahwa gua adalah sisa pelarutan yang terbentuk ketika gerakan air permukaan memasuki zona lemah batuan.

Proses seperti tersebut di atas berlangsung terus dan setelah bukit-bukit sinoidsal mengalami proses karstifikasi, maka lubang yang terdapat di bukit karst berfungsi sebagai voclus dan pnore. Pada awalnya rongga suatu gua merupakan sungai bawah tanah, namun oleh adanya gerak-gerak pengangkatan dan pergeseran, maka rongga tersebut menjadi sebuah lubang di tebing-tebing bukit karts. Akibat pengangkatan ini, sungai bawah tanah tersebut terus menurun, memasuki terowongan di bawah bukit dan bekas sungai tersebut kemudian berubah menjadi gua dan dalam kurun waktu tertentu gua bentukan di bukit karts tersebut dihuni oleh manusia pada pase sosial-ekonomi Masa Berburu dan Mengumpul Makanan Tingkat Lanjut (Simanjuntak 2002:131-132).

Pada kegiatan penelitian yaitu ekskavasi th.1994 antara lain telah menemukan data baru bahwa pada lapisan Gua Hunian Song Terus serta Gua Hunian Tabuhan telah ditemukan lapisan hunian berumur 45.000 tahun dan berlanjut hingga 30.000 tahun yang lalu, sehingga Gua Hunian Song Terus diketahui sebagai salah satu gua hunian tertua di Kawasan Asia Tenggara (Simanjuntak 2002:82) dan merupakan pendaratan hunian terawal Homo sapiens di Kawasan Asia Tenggara (Kompas 13 Agustus 2017).

Berdasarkan hasil penelitian ekskavasi tuntas dapat dikemukan bahwa lapisan paling tua mengandung lapisan bekas hunian berumur 180.000 tahun yang lalu. Lapisan ini merupakan lapisan anthropik yaitu lapisan hunian terbuka yang telah mengalamai reworking. Artefak yang ditemukan telah mengalami proses trasformasi lewat endapan sungai dan sebagai alat-alat lithik telah mengalami pembundaran walaupun sebagian lainnya tergolong masih segar. Lapisan di atasnya mengandung lapisan hunian yang berumur 300.000 tahun yang lalu. Pada lapisan ini mengandung jenis temuan alat-alat lithik seperti alat serpih, serpih batu dan lapisan ini disebut lapisan Terus. Pada lapisan di atasnya merupakan lapisan hunian berumur 300.000 tahun hingga 60.000 tahun yang lalu kemudian disusul lapisan Tabuhan berumur antara 60.000 tahun hingga 12.000 tahun yang lalu. Temuan penting pada lapisan hunian Tabuhan berupa sisa-sisa tulang binatang serta alat-alat serpih. Lapisan Tabuhan kemudian disusul lapisan hunian Keplek berumur sekitar 12.000 tahun hingga 6.500 tahun yang lalu. Pada lapisan hunian Keplek ini ditemuan temuan penting yaitu penguburan manusia dengan posisi terlipat disertai bekal kubur seperti halnya penguburan manusia tipe Sampung, Ponorogo. Selain itu juga ditemukan alat-alat tulang, alat serpih, kerang-kerangan baik kerang darat maupun laut dan sisa-sisa hewan buruan terdiri atas tulang-belulang binatang seperti Bovidae ,Cervidae, Suidae serta macaca maura (Simanjuntak 2002:151).

JPSI, Vol. 1, No., 1, 2018 
Berdasarkan hasil penelitian tersebut maka dapat direkonstruksi tentang proses hunian Gua Song Terus. Pada awalnya sekitar 180.000 tahun yang lalu Gua Song Terus merupakan hunian terbuka yang dapat dikaitkan dengan pase akhir kehidupan manusia purba Pithecanthrophus erectus - Pithecanthrophus soloensis. Menjelang akhir Kala Plestosen Atas awal Holosen sekitar 300.000 yang lalu, Gua Song Terus telah menjadi hunian pertama manusia Homo sapiens di Kawasan Asia Tenggara yang telah mengembangkan budaya tradisi mesolitik dan telah mengembangkan hunian sementara. Hal ini berlangsung hingga kurum waktu 120.000 tahun hingga 60.000 tahun yang lalu. Menjelang kurun waktu 60.000 tahun hingga 12.000 tahun yang lalu gua hunian Song Terus secara intensip dijadikan hunian sekaligus perbengkelan pembuatan alat-alat terutama alat-alat serpih dan juga telah digunakan sebagai pangkalan hasil perburuan hewan-hewan darat. Pada kurum waktu 12.000 tahun hingga 6.500 tahun yang lalu gua Song Terus masih digunakan sebagai tempat hunian serta perbengkelan secara intensip dan pada pase perkembangan ini manusia penghuni Gua Song Terus telah mengenal religi awal yakni telah mengenal tata cara adat penguburan mayat. Dalam pase perkembangan ini juga telah mengembangkan strategi berburu hewan laut seperti berburu kerang laut disamping juga mengembangkan strategi berburu hewan-hewan darat besar seperti Bovidae, Cervidae, Suidae serta Macaca maura.

Dari hasil penelitian dari beberapa peneliti tersebut, dapat diketahui bahwa Cagar Budaya Gua Hunian Song Terus dapat dipakai sebagai salah satu penunjang media pendidikan tentang representasi kehidupan sosial-ekonomi, manusia praaksara pase Masa Berburu dan Mengupul Makakan Tingkat Lanjut. Perlu diketahui bahwa Gua Hunian Mesolitik Song Terus merupakan salah satu gua hunian dari 55 gua hunian mesolitik yang ditemukan di daerah Punung, Pacitan. Dari ke-55 gua hunian yang berhasil telah didata, sebanyak 8 gua hunian telah diteliti secara intensip. Gua-gua hunian yang dimaksud yaitu gua hunian Song Keplek, Gua Barholo, Song Agung, Song Gupuh, Gua Gunung Gede, Gua Tahuhan, dan Gua Dono. Dengan demikian Cagar Budaya Gua Hunian Mesolitik Song Terus merupakan salah satu jenis gua hunian mesolitik di daerah Punung, Pacitan dan juga merupakan salah satu penunjang media pendidikan yang merepresentasikan fase kehidupan sosial-ekonomi manusia praaksara di Indonesia; terutama pada pase perkembangan Masa Berburu dan Mengumpul Makanan Tingkat Lanjut .

\section{Situs Perbengkelan Neolitik Ngrijangan}

Dipandang dari kepadatan situs dan tinggalan yang dikandungnya, secara pasti dapat dikemukakan bahwa Gunung Sewu termasuk situs Perbengkelan Neolitik Ngijangan merupakan daerah privilege yang paling kaya dan yang terpenting dalam peninggalan neolitik di Nusantara. Puluhan bahkan mungkin ratusan situs neolitik tersebar di 
daratan di sela-sela perbukitan karts dengan hamparan sisa perbengkelan yang sangat padat dan luas, khususnya di bagian timur Gunung Sewu, meliputi daerah Punung, Donorojo dan Pringkuku. Aspek yang paling menonjol dari situs-situs tersebut adalah sisasisa kegiatan perbengkelan yang sangat padat merupakan tumpukan rijang untuk membuat beliung persegi dan mata panah (Simanjuntak 2002:197-1999).

Keberadaan situs neolitik di wilayah Gunung Sewu, pertama kali dilaporkan oleh Van Stein Callenfels yang melakukan survei ke daerah ini pada tahun 1927. Beliau mencatat lebih dari 100 situs perbengkelan neolitik dan melakukan ekskavasi beberapa di antaranya, namun tidak berhasil menemukan hasil yang meyakinkan. Kecuali beliau menemukan serpihan-serpihan yang tersebar hingga kedalaman 2 meter (Stein Callenfels 1932). Situs yang dilaporkan oleh Van Stein Callenffels pada saat sekarang, hampir semua tidak dapat teridentifikasi kembali, hanya ada 47 situs neolitik yang dapat diidentifikasi kembali. Ke-47 situs neolitik tersebut merupakan situs terbuka dengan temuan pokok berupa serpihan-serpihan rijang sebagai buangan dalam proses pembuatan beliung persegi, benda-benda yang dihasilkan seperti beliung persegi, mata panah serta alat-alat lain seperti perkutor, batu asah, kereweng serta bandul.

Situs-situs neolitik di atas memeiliki luas yang berfariasi sebagai refleksi dari besarnya kegiatan yang pernah berlangsung. Situs yang tergolong besar dapat mencapai luas berhektar-hektar seperti situs Padangan, Ngrijang, Ngrijangan serta situs Ngrijangsengon. Adapun situs lain seperti situs Nangka, Tukluk Panggang, Ploso dan Druju hanya terbatas pada sebidang lahan.

Keberadaan beberapa situs tersebut, umumnya mempunyai keterkaitan erat dengan kondisi bentang alam. Untuk situs yang luas, biasanya menempati bentangan daratan, sedangkan keberadaan situs sempit, berkaitan dengan bentangan lereng perbukitan. Lokasi situs juga mempunyai keterkaitan yang erat dengan ketersediaan batuan rijang yang merupakan bahan utama pembuatan beliung ataupun mata panah. Batun rijang ini tersedia dalam bentuk bungkal-bungkal atau masih menyatu dengan batuan induk di sekitar situs. Dalam hal ini, kegiatan perbengkelan neolitik merupakan hasil adaptasi manusia penghuninya terhadap keberadaan sumber bahan batuan rijang yang sangat melimpah (Simanjuntak 2002:200-201).

Penelitian intensif yakni ekskavasi Situs Perbengkelan Neolitik Ngrijangan antara lain dilakukan oleh Balai Arkeologi Yogyakarta pada tahun 1988. Ekskavasi team Balai Arkeologi Yogyakarta, menghasilkan serpihan rijang yang sangat padat, berbagai bentuk tahapan pengerjaan beliung persegi, mata panah, dan perkutor hingga kedalaman $80 \mathrm{~cm}$ dari permukaan tanah (Handini \& Widianto, 1998). Selanjutnyan suvei intensip dilakukan 
Daud Aris Tanudirjo pada tahun di situs Bomo-Teleng. Penelitian menghasilkan pemahaman tentang aspek perilaku masyarakat pendukungnya, terutama berkaitan dengan eskploitasi keruangan dan proses teknologi pembuatan beliung persegi (Tanudirjo 1991).

Penelitian lanjutan dilakukan oleh Bidang Prasejarah, Pusat Penelitian Arkeologi Nasional dalam rangka Proyek Gunung Sewu : Exploitation in The Holocene. Penelitian didahului dengan eksplorasi, penelitian dilanjutkan dengan ekskavasi di beberapa situs antara lain Situs Ngrijangan, Ngrijangansengon dan situs Padangan. Secara umum ketiga situs mempunyai persamaan temuan yakni ditemukan puluhan ribu serpihan-serpihan rijang pada permukaan tanah hingga kedalaman terakhir, sebagai sisa kegiatan pembuatan beliung persegi. Temuan lainnya yaitu beliung persegi dalam beberapa tahap pengerjaan, perkutor dari batu pebble sebagai alat pemangkas Temuan artefak non-perbengkelan antara lain berupa batu pipisan, bandul, sisa pembakaran dan kereweng. Temuan terakhir ini terbatas pada lapisan atas.

Dalam jangkauan penelitian tersebut, termasuk Situs Perbengkelan Neolitik Ngrijangan diketahui bahwa luas situs ini mencapai sekitar 25.000 meter persegi dan menempatai bentangan dataran pada kemiringan $3-10$ ․ Pada permukaan tanah yang saat ini merupakan lahan pertanian tersebar sisa perbengkelan secara melimpah berupa serpihan-serpihan rijang sangat padat. Batuan penyusun di situs perbengkelan ini tersusun dari batuan gamping singkapan berwarna putih keabu-abuan. Bertekstur non klastik dengan struktur tidak berlapis, komposisi mineral adalah karbonat (CaCO 3). Berdasarkan genesanya, batuan gamping ini termasuk batuan sedimen kemis dan kesebandingan dengan formasi Wonosari-Punung yang menampakkan umurnya dari Miosen Tengah-Pliosen. Selain itu batuan gamping, di situs ini juga terdapat batuan rijang dan meta gamping yang didayagunakan untuk bahan pembuatan beliung serta mata panah (Simanjuntak 2002:202).

Kegiatan penelitan yakni ekskavasi situs Perbengkelan Neolitik Ngrijangan, berhasil memberi gambaran tentang temuan dan stratigrafi. Hingga kedalaman antara 180-210 $\mathrm{cm}$, terlihat 3 lapisan tanah: (1) berupa lempung coklat kekuningan, (2) berupa lempung coklat kemerahan dan (3) lapisan berupa lempung coklat kekuningan. Ketiga lapisan tersebut mengandung temuan sisa perbengkelan berupa serpihan-serpihan rijang yang sangat padat, beliung dalam bebarpa tahap pengerjaan, perkutor, sisa pembakaran, batu pipisan, bandul, dan mata panah. Khusus kereweng terbatas di lapisan atas dan tengah. Kegiatan perbengkelan paling tidak telah berlangsung di sekitar $2.100 \pm 220$ BP seperti ditampakkan oleh hasil pertanggalan C14 terhadap arang pada kedalaman $120 \mathrm{~cm}$ pada lapisan kedua (Simanjuntak 2002:202-203).

Berdasarkan paparan tersebut di atas Situs Perbengkelan Neolitik Ngrijangan mempresentasikan salah aspek kehidupan sosial-ekonomis neolitik Gunung Sewu. Kehidupan 
neolitik yang dimaksud memiliki karakter khas dalam hal orientasi geografis, aspek teknologis dan kronologis. Orientasi geografis dimaksudkan sebagai pemilihan bentang lahan tertentu sebagai pusat-pusat kegiatan atau hunian. Bukti-bukti yang diperoleh menunjukkan adanya dua pola geografis dalam perkembangan neolitik di daerah ini. Pada awal perkembangannya, neolitik terpusat di gua-gua dan ceruk alam sebagai budaya lanjutan dari budaya preneolitik, setelah itu berpindah ke bentang alam terbuka di daratan dan lereng perbukitan. Perpindahan dari gua ke alam terbuka, agaknya lebih didasarkan oleh kebutuhan yang berhubungan dengan perkembangan teknologi. Daratan dan lerengan perbukitan dimana batu rijang mudah didapat untuk bahan pembuatan beliung menjadi kondisi pilihan untuk hunian dan sekaligus untuk perbengkelan dibanding di dalam gua yang membutuhkan pencarian bahan baku di sekitarnya. Kemajuan teknologi juga kemungkinan telah dapat memanfaatkan pepohonan untuk bangunan tinggal sederhana di sekitar perbengkelan.

Munculnya neolitik di wilayah Gunung Sewu berlangsung di dalam gua. Pertanggalan radio karbon dari Gua Braholo dan Song Keplek masih sangat terbatas, namun untuk sementara dapat memberikan gambaran tentang masa perkembangn budaya neolitik di kawasan Gunung Sewu termasuk juga perkembangan situs perbengkelan neolitik Ngrijangan. Budaya preneolitik skhir di Song Keplek bertanggal 3.260 \pm 110 BP, sedangkan di Gua Braholo neolitik telah dimulai pada $4.120 \pm 100$ BP. Data pertanggalan absolut ini menunjukkan bahwa neolitik kawasan Gunung Sewu diduga telah berkembang di sekitar 4.000 BP. Sampai kapan neolitik bertahan di dalam gua, juga masih memerlukan penelitian lanjutan, namun mengamati lapisan budaya yang tergolong tipis, diduga berlangsung hingga sekitar 2.000 BP. Di Song Keplek, neolitik berakhir sekitar $790 \pm 100$ BP, sementara di Gua Braholo, neolitik berakhir sekitar pada $3.050 \pm 100$ BP. Setelah waktu itu terjadi perubahan orientasi dengan beralihnya pusat-pusat kegiatan dan hunian ke bentang alam terbuka. Sejak itu pula hunian gua telah berakhir, menuju pada alam terbuka pada dataran terbuka dan lereng-lereng bukit (Simanjuntak 2002:207), yang kemudian dikenal dengan istilah kehidupan neolitik pada alam terbuka (open sites).

Perubahan kehidupann tradisi neolitik dari gua hunian ke alam terbuka, telah membawa perubahan serta dinamika baru kehidupan tradisi neolitik. Suatu yang menonjol tampak dalam lokasi pusat-pusat kegiatan yang berhubungan dengan pengembangan teknologi litik. Bentang alam yang dipilih sebagai sentral kegiatan sehari-hari adalah daratan dan lereng perbukitan landai yang sangat kaya akan sumber daya baku batuan rijang. Perpindahan ini agaknya membawa dampak yang sangat luas terhadap berbagai dimensi kehidupan. Dalam dimensi keruangan sangat menonjol adanya ekspansi horizontal untuk sentral kegiatan, khususnya di bagian timur Gunung Sewu. Ratusan situs neolitik terma- 
suk Situs Ngrijangan tersebar di daerah Punung dan sekitarnya menunjukkan adanya peningkatan populasi yang berarti dan membentuk kelompok-kelompok masyarakat yang menempati berbagai daratan dan lereng di antara bukit-bukit karts. Dalam dimensi teknologi tampak suatu loncatan yang sangat berarti, yaitu dalam pengembangan industri litik untuk mengahasilkan beliung dan mata panah. Produk teknologi preneolitik seperti alat serpih-bilah hampir tidak ditemukan lagi. Melalui penguasaan teknik-teknik pemangkasan, berkembang kelompok-kelompok perbengkelan.

Dari hasil penelitian diketahui bahwa pembuatan beliung persegi merupakan industri utama neolitik di kawasan Gunung Kidul termasuk Situs Perbengkelan Neolitik Ngrijangan. Pada dasarnya lebih diutamakan untuk menghasilkan calon-calon beliung persegi, walaupun dalam beberapa hal dihasilkan beliung siap pakai. Pembuatan beliung persegi meliputi suatu proses panjang mulai dari pencarian dan pengumpulan bahan baku, tahap pemangkasan : pembentukan awal-pembentukan lanjut-penghalusan, tahap penyelesaian, hingga tahap pemasaran. Pada tahap pengumpulan bahan baku, tidak memerlukan pekerjaan berat, sebab bahan baku melimpah ruah tersebar di sekitar perbengkelan dalam bentuk bungkal-bungkal. Penemuan tumpulan bungkal rijang di kotak LU I di Ngrijang Sengon dan di kotak EE1 dan BBXXIX di Ngrijangan membuktikan adanya tahap pencarian dan pengumpulan bahan baku, mendahului tahapan pembuatan beliung.

Secara umum teknologi pembuatan beliung dapat dibedakan dalam 3 tahap. Teknologi pembuatan beliung diawali dengan tahapan pembentukan awal yakni suatu bungkal bahan dipangkas dari berbagai sisi untuk menciptakan bentuk dasar persegi. Pada tahapan ini bentuk calon beliung masih kasar dan tebal dengan bekas-bekas pangkasan memanjang dan melebar. Calon beliung yang dihasilkan masih berukuran jauh lebih besar dan beliung yang diinginkan dan ketebalan belum sama di seluruh bagian. Pada bagian permukaannya masih terlihat kortek atau kulit batu. Pada proses pembentukan lanjut dimulai dengan melakukan pemangkasan-pemangkasan ringan dan dihasilkan calon beliung yang lebih halus dengan ukuran yang mendekati beliung yang diinginkan. Kulit batu atau korteks hampir sudah tidak ada lagi dan tajaman sering sudah dibentuk lewat pemangkasan monofasial. Pada akhir tahapan ini calon beliung sudah menampakkan bentuk beliung yang diinginkan. Setelah proses ini dilanjutkan dengan proses penggosokan serta pengumpaman.

Seperti telah dijelaskan di muka bahwa bengkel-bengkel neolitik di Gunung Sewu mencapai 47 situs, dengan demikian dapat dikemukakan bahwa sebaran itu termasuk sangat banyak. Sehubungan dengan hal itu, melihat banyaknyan situs pusat-pusat perbengkelan neolitik, dapat disimpulkan bahwa daerah Punung, Pacitan dan sekitarnya menjadi pusat industri beliung pada fase perkembangan sosial-ekonomi Masa Bercocok 
Tanam. Hal ini menjadi suatu indikator bahwa pada saat itu telah terjadi ekspor calon beliung ke luar daerah Punung, Pacitan. Dengan demikian pada fase perkembangan Masa Bercocok Tanam di Punung, Pacitan telah tercipta suatu perdagangan antara komunitas industri dan komunitas luar dan sekaligus menunjukkan adanya mobilitas di antara produsen beliung persegi dengan konsumen.

Selain calon beliung persegi, produk lain dari perbengkelan adalah mata panah. Produk yang dihasilkan agaknya tidak semelimpah produk calon beliung. Sebuah catatan perlu dikemukakan bahwa di kawasan Gunung Kidul terdapat 2 jenis mata panah yaitu mata panah yang dibuat di hunian gua dan mata panah yang dibuat di hunian terbuka. Berdasarkan hasil penelitian diketahui bahwa suatu perbengkelan yang memproduksi calon beliung dan mata panah sekaligus yaitu ada di Situs Ngrijangan, Melikan dan Situs Gunung Semut. Kemudian situs-situs yang khusus memproduksi beliung persegi yaitu Situs Padangan dan Nrijangan, Adapun situs perbengkelan yang khusus memproduksi mata panah yaitu Situs Blawong, Ngaglik, Ngaglik Lor, Mojo, Jati Sari, Sembungan dan Jelok (Simanjuntak 2002:211).

\section{BENTANGAN CAGAR BUDAYA PRAAKSARA PACITAN SEBAGAI MEDIA PENUNJANG PENDIDIKAN}

Berdasarkan uraian tentang karakteristik Cagar Budaya Situs-Situs Praakasara Pacitan tersebut di atas maka dapat dibahas, bagaimanakah situs-situs praaksara tersebut dapat dijadikan sebagai media penunjang pendidikan. Telah dijelaskan di muka bahwa Cagar Budaya Kali Baksoka telah dideskripsikan sebagai situs paleolitik yang kemudian di dunia internasional dikenal dengan Kebudayaan Pacitan atau Pacitanian sebagai bagian dari kelompok kapak-perimbas-penetak di Asia Timur. Telah diakui dunia bahwa Cagar Budaya Kali Baksoka ditempatkan sebagai salah satu situs di Asia Tenggara yang merepresentasikan teknologi paleolitik pase perkembangan sosial-ekonomi Masa Berburu dan Mengumpul Makanan Tingkat Sederhana. Dari hasil penelitian seperti telah diuraikan di atas, lingkungan Cagar Budaya Kali Baksoka merupakan representasi lingkungan geologis yang terjadi pada Kala Plestosen Atas sekitar 1,6 juta tahun yang lalu hingga 180.000 tahun yang lalu serta dicirikan oleh Fauna Trinil. Dengan demikian lingkungan geologis Cagar Budaya Kali Baksoka merupakan lingkungan yang pernah ditempati oleh manusia purba yang hidup pada Kala Plestosen Atas yaitu Pithecanthrophus erectus hingga Pithecanthrophus soloensis. 
Bardasarkan penelitian sebaran alat-alat lithik yang kebanyakan ditemukan di dasar Kali Baksoka serta endapan tebingan Kali Baksoka didapat suatu kesimpulan bahwa lingkungan Kali Baksoka merupakan situs hunian terbuka manusia purba serta situs perbengkelan. Dengan demikian lingkungan geologis Kali Baksoka merepresentasikan model lingkungan yang pernah dihuni oleh manusia purba Kala Plestosen Tengah. Dilihat dari temuan alat-alat paleolitik yang kemudian dikenal dengan Kebudayaan Pacitan dapat diketahui bahwa manusia purba kala itu telah memproduksi berbagai jenis alat-alat yaitu kapak perimbas, kapak penetak, proto kapak genggam, alat serpih dan kapak genggam. Secara sederhana alat-alat itu dapat digolongkan menjadi dua jenis yaitu alat-alat serpih dan alat-alat batu inti. Dari sebaran alat-alat lithik juga dapat diketahui jenis-jenis batuan yang digunakan sebagai bahan baku alat yaitu terdiri atas batuan chert atau batu rijang, jasper atau batuan sedimen berwarna merah, metagamping, fosil kayu dan batuan gamping. Dengan demikan manusia purba kala itu telah mengenal teknologi utamanya pemilihan bahan baku, proses pembuatan alat, proses pemakaian alat dan pengenalan hewan perburuan.

Uraian tersebut bila dikaitkan dengan Kompetesi Dasar (KD) 3.1, Cagar Budaya Situs Paleolithik Kali Baksoka merupakan representasi media pembelajaran tentang kehidupan sosial-ekonomi manausia praaksara pada pase perkembangan Masa Berburu dan Mengumpul Makanan Tingkat Sederhana. Dengan demikian, cagar budaya tersebut dapat dipakai sebagai media penunjang pendidikan utamanya sebagai penujang media pembelajaran Sejarah Indonesia.

Selanjutnya, Cagar Budaya Situs Gua Hunian Song Terus dalam uraian tersebut di atas dideskripsikan sebagai representasi gua hunian pada mesolitik pada fase perkembangan sosial-ekonomi Masa Berburu dan Mengumpul Makanan Tingkat Lanjut dengan budaya tradisi mesolitik. Dari situs ini dapat digali berbagai informasi yang merepresentasikan kebudayaa mesolitik yang telah berkembangan sekitar 60.000 tahun yang lalu hingga kurum waktu 6.500 tahun yang lalu. Bahkan pada penelitian terbaru situs gua hunian ini diketahui sebagai salah satu gua hunian tertua di kawasan Asia Tenggara dan merupakan pendaratan pertama jenis manusia Homo sapiens yang bermigrasi ke kawasan Asia Tenggara. Situs gua hunian ini juga mengandung data tentang proses kehidupan terbuka kala Plestosen ke hunian gua pada awal Holosen. Kemudian juga dapat dirunut tahapan-tahapan kehidupan bercorak mesolitik, hingga manusia kala itu mengenal tata cara adat penguburan mayat sebagai bukti awal munculnya kehidupan religi.

Pada konteks lain situs gua hunian tersebut juga merekam bukti-bukti eksploatasi lingkungan sekitaran gua, dataran pegunungan gamping dan lingkungan marine. Berbagai jenis hewan buruan juga dapat ditemukan di situs ini. Dari uraian tersebut, maka Cagar Budaya Situs Gua Hunian Song Terus dapat disempulkan bahwa situs gua hunian 
tersebut sebagai salag satu representasi kehidupan sosial-ekonomi fase Masa Berburu dan Mengumpulk Makanan Tingkat Lanjut. Dengan demikian berdasarkan Kompetensi Dasar (KD) 3.1, Cagar Budaya Situs Gua Hunian Song Terus dapat dijadikan penunjang utama media pendidikan. Hal ini disebabkan keberadaan situs tersebut merepresentasikan kehidupan sosial-ekonomi manusia praakasa pada pase perkembangan Masa Berburu dan Mengumpul Makanan Tingkat Lanjut (Soejono 1996:6-7).

Adapun, Cagar Budaya Situs Perbengkelan Ngrijangan dalam uraian tersebut di atas ditempatkan sebagai salah satu situs perbengkelan neolitik pase perkembangan sosialekonomi Masa Bercocok Tanam. Dari situs ini dapat ditampilkan beberapa aspek kehidupan manusia praakasara tradisi neolitik yaitu menggambarkan tentang pusat perbengkelan neolitik yaitu pembuatan calon beliung dan mata panah di Punung, Pacitan. Situs yang luasnya hingga $25.000 \mathrm{~m}^{2}$ telah memberikan pengetahuan yang luar biasa, betapa intesipnya serta kompleksnya industri calon beliung persegi serta mata panah pada waktu itu. Temuan yang sangat melimpah berupa serpihan-serpihan rijang, bungkal-bungkal batuan rijang serta melimpahnya sebaran calon beliung persegi serta mata panah telah memberikan gambaran bahwa proses industri neolitik pada Masa Bercocok Tanam merupakan kebutuhan pokok untuk mendukung kegiatan sosialekonomis yaitu pertanian awal. Di sisi lain situs itu juga telah memberikan gambaran nyata bahwa teknologi pembuatan beliung harus memperhatikan tersedianya sumber daya bahan baku yaitu batuan rijang maupun batuan gamping kersikan. Proses pembuatan beliung diawali dengan pengumpulan bungkal-bungkal batuan, kemudian dilanjutkan proses pemangkasan awal, pemangkasan ringan dan penghalusan dan baru diperdagangkan di sekitar Punung, bahkan di luar daerah Punung seperti situs neolitik terdekat seperti Kendeng Lembu, Banyuwangi. Rekonstruksi tentang berbagai ragam aspek kehidupan tradisi neolitik ini dapat diungkap serta dapat damatai melalui tinggalan di Cagar Budaya Situs Perbengkelan Ngrijangan (Simanjuntak, 2002:210-222).

Berdasarkan analisis tersebut, maka Cagar Budaya Situs Perbengkelan Nrijangan, Punung, Pacitan, ditinjau dari Kompetensi dasar (KD) 3.1 dapat digunakan serta dimanfaatkan sebagai penunjang media pendidikan yaitu pembelajaran sejarah, biologi, IPS dan pembelajaran geografi. Hal ini didasarkan atas beberapa bukti bahwa Cagar Budaya Situs Perbengkelan Ngrijangan sebagai salah satu situs yang merepresentasikan beberapa aspek kehidupan sosia-ekonomi manusia praaksara pada pase perkembangan Masa Bercocok Tanam (Soejono 1996:6-7). Dengan demikian perlunya pelestarian situs agar bisa dimanfaakan sebagai media serta sumber belajar dalam kaitannya model pembelajaran outdoor leraning yang selama ini sedang di galakkan di berbagai institusi pendidikan termasuk institusi pendidikan di Kabupaten Pacitan (Irawan.G.E, 2015). 


\section{SIMPULAN}

Dalam proses pembelajaran antara lain memerluakan media pembelajaran dan proses pembelajaran tanpa media pembelajaran dirasa tidak akan berlangsung dengan baik. Dalam beberapa kajian literatur media pembelajaran dapat berupa media elektronik atau mesin pembelajaran lainnya. Dalam model pembelajaran outdoor learning media pembelajaran berupa kejadian sebenarnya yang berada di alam, cotohnya misalnya Kebun Raya, Kebun Binatang , Bentang Alam seperti sungai, danau dan lain-lainya. Dalam konteks pembelajaran Sejarah, media pembelajaran model out door learning adalah museum, situs bersejarah termasuk dalam hal ini adalah Cagar Budaya Pacitan yaitu Cagar Budaya Situs Paleolitik Kali Baksoka, Cagar Budaya Situs Gua Hunian Mesolitik Song Terus dan Cagar Budaya Situs Perbengkelan Neolitik Ngrijangan, Punung. Situs-situs itu dapat dijadikan media pembelajaran model pembelajaran outdoor leraning yang sangat potensial dan memenuhi syarat seperti yang dianjurkan dalam Kompetesnsi Dasar (KD) 3.1.

Cagar Budaya Situs Kali Baksoka merepresentasikan beberapa aspek kehidupan sosial-ekonomi manusia praaksara pase perkembangan teknologi paleolitik tingkatan kehidupan Masa Berburu dan Mengumpul Makanan Tingkat Sederhana. Lingkungan situs merepresentasikan lingkungan alam Kala Plestosen Tengah yang menjadi tempat hunian terbuka manusia purba yaitu Pithecanthroiphus erectus hingga Pithecanthrophus soloensis, walaupaun kedua manusia fosil itu belum ditemukan di Situs Paleolitik Kali Baksoka. Kemudian Cagar Budaya Situs Gua Hunian Mesolitik Song Terus merepresentasikan beberapa aspek kehidupan sosial-ekonomi pase perkembangan kebudayaan mesoilitik pada Masa Berburu dan Mengumnpul Makanan Tingkat Lanjut. Gua Song Terus merupakan salah satu situs gua hunian dari 70 situs gua hunian yang tersebar di daerah Punung, Pacitan dan situs gua tersebut merupakan situs gua hunian mesolitik yang tertua di kawasan Asia Tenggara. Cagar Budaya Situs Perbengkelan Neolitik Ngrijangan, Punung merupakan salah satu situs perbengkelan dari 47 situs perbengkelan yang tersebar di daerah Punung. Situs ini merepresentasikan pase perkembangan kebudayaan tradisi neolitik utamanya yang menyangkut perbengkelan beliung dan mata panah pada Masa Bercocok Tanam. Berdasarkan bukti-bukti maka dapat disimpulkan bahwa Cagar Budaya Pacitan yang terdiri atas Cagar Budaya Kali Baksoka, Cagar Budaya Gua Hunian Mesolitik 
Song Terus dan Cagar Budaya Situs Perbengkelan Neolitik Ngrijangan merupakan penunjang media pembelajran Sejarah Indonesia sesuai dengan Kompetensi Dasar (KD) 3.1 (Irawan, G. E.,2015.:2-15).

\section{RUJUKAN}

Bastra, G.J. 1976. Contribution to the Study of the Paleolithic Patjitan Culture, Java, Indonesia. Leiden: E.J. Brill

Irawan, G.E., 2015, Pengembangan Media Pembelajaran Peta Digital Berbasis Macromedia Flash 8.0 Pada Pokok Bahasan Kehidupan Masa Praaksara di Indonesia untuk Meningkatkan Hasil Belajar Siswa Kelas VII/I SMP Negeri I Malang (skripsi S.1) tidak terbit, Malang: Jurusan sejarah, FIS, Universitas Negeri Malang.

Handini, R., \& Widianto, H. 1998. GuaBraholo: Karakter Hunian Mikro pada Awal Kala Holosen di Gunung Sewu. Berkala Arkeologi. XIX (1).

Heekeren, H.R.van., 1954, " New investigation on the lower paleolithic Pavitan Culture in Java" dalam Berita Dinas Purbakala I, hlm. 1- 42, Jakarta: Dinas Purbakala, Republik Indonesia.

Heekeren, H.R.van., 1957, "The Stone Age of Indonesia" dalam Verhandelingen van Het Koninklijk Instituut voor Taal-Land -en Volkenkude Deel XXI, Martinus Nijhoff: S.Gravenhage

Kementrian Kebudayaan dan Pariwisata, Direktorat Sejarah Jendral Sejarah dan Purbakala, 2013. Undang-Undang Republik Indonesia Nomor 11 Tahun 2010 Tentang Cagar Budaya, Jakarta : Kementrian Kebudayaan dan Pariwisata

Koenigswald, G.H.R. 1936. Ein fossiler Hominide aus dem Altpleistocan Ostjavas. De Ingineur ned.-Indie, 4, 149-157.

Koenigswald, G.H.R. 1937. A Review of the Stratigraphy of Java and Its Relations to Early Man. Early Man. JB Lippincott, London, 23-32.

Lehman, H. 1936. Morphologiche Studien auf Java. Stuttgard: Engelhorn.

Movius,JR, H.L,1948, " The Lower Paleolithic Culture of Southern and Eastern Asia", Trans.American Phil.Society, 38 (4) hlm.329-340. 
Samudra. 1983. Geologi dan Studi Bahan Galian di Kecamatan Karangmojo da Semanu, Kabupaten Gunungkidul. Skripsi. Tidak diterbitkan. UPN "Veteran" Yogyakarta.

Sedyawati,E., 2014, "Pengertian "Tangible" dan "Intangible" dalam Wacana tentang Warisan Budaya", dalam Kebudayaan di Nusantara : dari Keris Tor-to sampai Industri Budaya, Depok:Komunitas Bambu, hlm. 441-446

Soejono, R.P, 1984, "Jaman Prasejarah di Indonesia" dalam Sejarah Nasional Indonesia Jilid I, Jakarta: Balai Pustaka, Departemen Pndidikan dan Kebudayaan

Soejono, R.P, 1996, " Tinjaun tentang Perkerangkaan Prsejarah Indonesia" dalam Berita Prasejarah No.1, Tahun I, Jakarta ; Asosiasi Prehistorisis Indonesia (API), hlm.1 - 11

Soejono, R.P, 2002, "Tinjaun Tentang Perkerangkaan Prasejarah Indonesia" dalam Aspek-Aspek Arkeologi Indonesia No.5, Jakarta: Pusat Arkeologi

Simanjuntak,T., 1995. "Cave Habitation During the Holocens Period in Gunung Sewu" dalam Aspek-Aspek Arkeologi Indonesia No.18, Jakarta: pusat penelitian Arkeologi Nasional.

Simanjuntak,T, 2002, Gunung Sewu in Prehistoric Times, Yogyakarta: Gadjah Mada University Press.

Suprapta, Blasius, 2017, "Model Pemanfaatan "Cagar Budaya" untuk Kesejahteraan Masyarakat : Studi Kaus : Even Malang Kembali" Sejarah dan Budaya : Jurnal Sejarah, Budaya dan Pengajarannya, 2017

Surono, B.T., Sudarno, I \& Wiryosujono. 1992. Geology of Surakarta-Giritontro Quadrangels, Java, scale 1:100.000. Bandung: Geological Research and Development Center.

Stein Callenfels, P.V.van 1932, "Note Préliminaire Sur Les Faoulles dns L'abri-sour-roche du Guwa Lowa á Sampung, dalam Homemage Premier Congres Prehistoire d'Extreme-Orient, Batavia : Albrecht \& Co

Tanudirdjo, D.A. Some Behavioural Aspects of the Bomo-Teleng Stone Adze Workshop Site in East Java (Indonesia). Thesis. Canberra: The Australia National University.

Van Bemmelen, R.W. 1949. Report on the Volcanic Activity and Volcanological Research in Indonesia during the Period 1936-1948. Bulletin Volcanologique, 9 (1), 329.

Widianto, H. 1983. “Kali Oyo dalam Kronologi Pertanggalan Plestosen” Skripsi Sarjana S1. 